\title{
Die (für mich) neue Welt der Hypervernetzung
}

\section{Jean Martin}

Dr. med., Mitglied der Redaktion

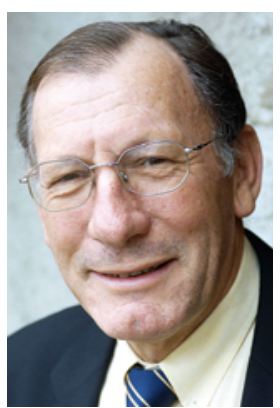

Vor kurzem war ich eine Woche auf den Kanaren, auf Lanzarote, der Insel der 300 Vulkane. Sechs Tage Wandern in einer Landschaft mit einer Vielfalt an Flora, Farben und Formationen. Ich habe dort Erstaunliches über die Humangeographie erfahren - darüber, wie sich der Mensch seiner Umwelt angepasst und Mittel und Wege gefunden hat, in ihr zu (über)leben.

Es geht mir jedoch um etwas anderes. Darum, wie "fremd» ich mich gefühlt habe mitten in einer netten Gruppe von etwa zwölf Personen, die meisten zwischen 35 und 55 Jahren alt. Beispielsweise, wenn ich sie nach der Rückkehr von einer Wanderung sofort auf ihre Laptops stürzen sah. "Weisst du, ich erhalte täglich hundert E-Mails und muss mich dann sofort darum kümmern.» Getoppt wurde dies noch durch Telefonate mit Kindern und Bekannten. Viele betrachten die Landschaften vor allem durch ihr Smartphone.

Meine Frau und ich haben das Glück, uns an Enkelkindern erfreuen zu können. Diejenigen, die zwischen 10 und 16 Jahren alt sind, verbringen enorm viel Zeit vor ihren Bildschirmen und Tablets. Im vergangenen Sommer war ich etwas sauer, als ich bei einer Reise nach Südeuropa feststellen musste, dass diese jungen Leute den ganzen (sonnigen) Tag in ihrem über Airbnb gebuchten Zimmer blieben, ohne sich für die Sehenswürdigkeiten oder Naturwunder um sie herum zu interessieren. Wenn ich per Bahn, Auto oder Flugzeug reise, sitze ich gern am Fenster, um mir die jeweilige Region anzusehen. Die jungen Leute scheinen sich nicht vorstellen zu können, dass man aus dem Fenster schauen kann - und der Grossvater macht sich unbeliebt mit seinen Bemerkungen.

Ich bin viel gewandert, habe Trekking-Touren unternommen und war sehr gern für einige Tage oder auch zwei bis drei Wochen unterwegs. Derweil lautete meine Devise: «Keine Nachrichten sind gute Nachrichten» ich schreibe noch Postkarten, sie kommen aber erst nach mir an. Ich bin oft allein, auch in den Bergen. Und ich musste feststellen, dass der Ausflug ohne Mobiltelefon auch Anlass zu Kritik gegeben hat (wenn ich daran denke, nehme ich jetzt mein «vorsintflutliches» Nokia mit). Ein Wanderer, der gerne allein unterwegs ist, schrieb einmal mit Bedauern, dass «man heute nicht einmal mehr das Recht habe, sich zu verirren». Andererseits konnte es noch bis vor etwa 25 Jahren vorkommen, dass Menschen ihre Gesundheit, ihr Leben oder die Verbindung zu nahestehenden Personen verloren, ohne ihren Standort mitteilen zu können (Beispiele: die wahre Geschichte des verfilmten Buches Into the Wild; die Auswanderungswelle nach Amerika, bei der Familienmitglieder verlorengingen, ohne die Chance, sich jemals wiederzufinden).

Heute erstaunt die existentielle Unentbehrlichkeit des Smartphones - mit Zugriff auf das gesamte universelle Wissen. Jüngst beobachtete ich, wie meine Begleiter bei jeder Frage (Pflanze, Geographie, Geschichte) sofort zu googeln begannen, aber im wahrsten Wortsinn absolut «verloren» waren, wenn sie ihr Gerät nicht dabei hatten. Das geht nah in Richtung Entzug und Abhängigkeit.*

Welche Konsequenzen lassen sich daraus ableiten? Die Evolution lässt sich nicht aufhalten, aber wir können (zumindest ein wenig) darüber nachdenken, dass wir uns im Alltag zu Cyborgs (Mischwesen aus Mensch und Maschine) entwickeln, nicht zuletzt auch dank der Medizin mit ihren unentbehrlichen Erfolge, u.a. Schrittmacher und Transplantate aus künstlichen Materialien - darunter auch künstliche Kniegelenke, mit denen auch meine Wenigkeit sehr zufrieden ist. In der Folge - so scheint

\section{«Unsere fünf Sinne werden nicht mehr so geschickt genutzt. Eine Vielfalt an Sensoren erfasst die Realität besser als wir.»}

mir - verändert sich unsere Weltsicht, unser Verständnis von der Umwelt. Welt und Umwelt werden nicht wie bisher auf direktem Wege begriffen, sondern immer mehr über technische Hilfsmittel. Logischerweise (?) kommen unsere fünf Sinne weniger zum Einsatz (sie verkümmern?). An ihre Stelle treten verschiedenste Sensoren und erfassen die äussere, aber auch die innere Welt - unsere biologischen Parameter - viel besser als wir. Aber nicht nur unsere Sinne verlieren an Bedeutung. Gleiches gilt auch für das Gedächtnis, denn Google kann uns problemlos per Klick alles sagen.

Liege ich komplett daneben? Ich wünschte, es wäre so! 